\title{
Cancer endocrinology through own experience: areas for further thought and development
}

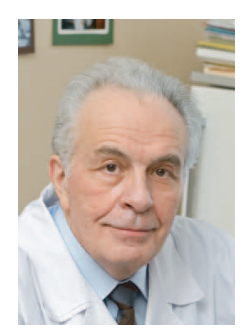

\section{Lev M Berstein}

Laboratory Oncoendocrinology, NN Petrov Research Institute of Oncology, Pesochny, St Petersburg, 197758, Russia = levmb@endocrin.spb.ru

Lev Berstein speaks to Natasha Galukande, Assistant Commissioning Editor. Lev Berstein is Chief of Laboratory of Oncoendocrinology at the Petrov Research Institute of Oncology, St Petersburg, Russia. His main scientific interests include mechanisms of hormonal carcinogenesis, studying risk factors of hormoneassociated tumors, and new approaches for prevention and treatment of the latter. As a clinician, he is involved in the management of cancer patients needing hormonal therapy or having endocrine pathology. Berstein has received several international distinctions (including an INTAS grant and UICC Translational Cancer Research Fellowship), serves as a Member of Council of the Russian Endocrine Association and is on the editorial boards of several international journals, including Future Oncology, was Guest Editor for a special focus issue of Expert Review of Endocrinology and Metabolism on hormones in breast and prostate cancer, and is a member of the European Association of Cancer Research and The Endocrine Society of the USA. His bibliography includes 11 monographs, 21 chapters and more than 200 papers in peer-reviewed journals. He graduated as a MD from Tartu University in Estonia and completed his PhD and Doctor of Medical Sciences degrees in cancer endocrinology at the NN Petrov Institute in St Petersburg (Russia).

\section{What sparked your interest in oncoendocrinology?}

In trying to remember the onset of my interest in oncoendocrinology, I realize that this occurred essentially by chance. I graduated from the School of Medicine at the famous Tartu University in Estonia (which was one of the republics of USSR in those times). In about the third year of studying there I became interested in 'pure' endocrinology. I attended the Tartu Endocrine Dispensary Clinic two- or three-times a week, took part in patient examinations and started to do some work (mostly related to thyroid pathology) at the laboratory there. A result of this was my first journal paper, which was published in 1963 in Problemy Endokrinologii (Problems in Endocrinology), in time for the last year of my medical apprenticeship began (it took 6 years then to complete medical education at the University). Time flew by, my studies were coming to completion, and I prepared myself to attend postgraduate courses in endocrinology at the Institute of Endocrinology in Moscow, Russia. Then, all of a sudden, - 'suddens' are quite common in everybody's life, as one knows - I had a proposal from the Institute of Experimental and Clinical Medicine (Tallinn, Estonia) to be recommended for postgraduate courses in cancer endocrinology at NN Petrov Institute of Oncology in St Petersburg, Russia (Leningrad in those times). I found out the name of the head of the laboratory in charge of the courses. The name was Vladimir Dilman. Shamefully, it originally meant nothing to me then. However, I easily discovered that his clinical and scientific interests were at the interface of two disciplines, endocrinology and oncology (actually, they were three, including gerontology, as it became apparent somewhat later). As a matter of fact, I did not contemplate that much and accepted the proposal. After almost five decades I realize that my decision, with regard to both specialty and mentor, was a lucky one. Dilman was at that time, and even more so later, a world-class researcher who suggested, in particular, several important concepts, such as 'the syndrome of cancrophilia', 'metabolic immunodepression', 'metabolic rehabilitation of cancer patients', 'the ontogenetic model of aging and age-related pathology', 'ageassociated elevation of the threshold of hypothalamic sensitivity to regulatory stimuli' and others. In fact, he was the first to use diabetic

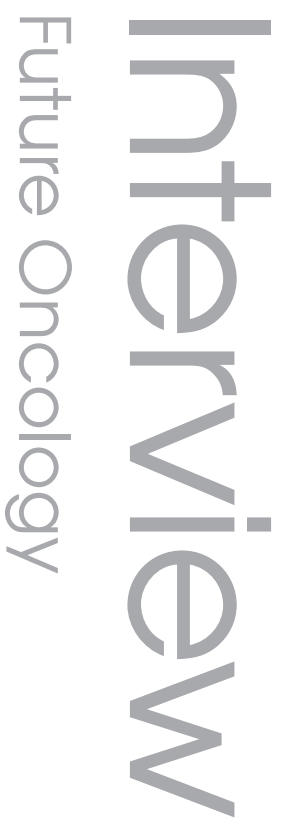

Future
Medicine 
biguanides in experimental and clinical oncology, and in lifespan extension. These ideas were published in top journals, including the Lancet [1], International Journal of Oncology, Journal of Theoretical Biology and the American Journal of Obstetrics and Gynecology.

The second name I cannot miss is Richard Santen (currently at the Division of Endocrinology, University of Virginia, VA, USA). It was not that he sparked my interest in cancer endocrinology; however, he did heat it up a good deal. In 1991, when he was already internationally renowned as an expert in the study of estrogens in breast cancer, he invited me to his laboratory (Pennsylvania University, PA, USA) to study aromatase in tumor tissues and blood mononuclears. Since then our friendship and collaboration continued to result in many research-related visits, projects and publications and, very importantly for me, in the perpetual feeding of my desire to contribute to this important oncological field, which, these days, attracts so much attention.

\section{What do you feel is the biggest challenge facing the field today?}

The answer to this question with regard to oncoendocrinology, as well as to other 'borderline' disciplines, cannot be simple. On the one hand, the mere integrative nature of endocrinology per se, which penetrates all fields of medicine, justifies its role in oncology. However, what is the first thing to be emphasized? In the most general sense, this must be a combination of basic and clinical studies, providing for knowledge transfer from basic to clinical, which has been known for quite a long time as 'translational research'. On the other hand, one may turn to a publication by the prominent biologist and geneticist David Botstein (Lewis-Sigler Institute for Integrative Genomics, NJ, USA; who was recently awarded with the Breakthrough Prize in Life Sciences), where he stated that "we need more basic biology studies, not less" and that "translational research aimed directly at treating disease" is not a panacea because we still do not know a lot of basic things [2]. When it comes to oncoendocrinology, the problem of different mechanisms and types of hormonal carcinogenesis is illustrative in this regard. This is a serious challenge because a longstanding belief is that hormones induce tumors by acting not as genuine carcinogens but as promoters. However, accumulating evidence makes it increasingly clear that some hormones, such as estrogens, may be transformed into metabolites that are able to damage DNA. Eventually, the oncoendocrinological community came to realize that estrogen-related carcinogenesis is a phenomenon, which has at least two types. However, it is still premature to translate its genotoxic aspect into clinical practice, although indirect attempts to confirm this idea in the clinic are known. On the whole, it is important for cancer endocrinology to become more accustomed to its significance in contemporary oncology. This awareness may be promoted by periodicals such as Endocrine-Related Cancer, Hormones and Cancer and, of course, Future Oncology.

\section{What do you feel is the biggest achievement of your career so far?}

The two aspects can be distinguished as a formal one and a scientific one. The first one, which is certainly related to science, includes my winning of the prestigious research grant, the so-called AstraZeneca-UICC Translational Cancer Research Fellowship (TCRF). Owing to this grant, I had the opportunity to work for 1 year, from the summer of 2001 to the summer of 2002, at Professor Santen's laboratory in Virginia, where I studied the mechanisms of cancer resistance to tamoxifen. In systematic experimental and clinical studies we were able to show that processes resulting in responses to tamoxifen as an agonist and the development of estrogen hypersensitivity of breast cancer cells could potentially be mechanistically linked and involve activation of MAPK signaling and the aromatase system [3]. As to science sensu stricto, my interests were focused (and I believe resulted in the most significant advances) on endocrine-genotoxic switching as a factor that increases the risk of tumor development through the predominant usage of a genotoxic type of hormonal carcinogenesis [4], on the association of different types of macrosomia (including newborn macrosomy) with cancer risk $[5,6]$, on the heterogeneity of obesity and diabetes as a factor that at times may modify predisposition to cancer in an opposing way $[7,8]$, and on the controversial role of antidiabetic biguanides as potential and, in a sense, selective means for cancer prevention and treatment $[9,10]$.

\section{- You serve as the Chief of Laboratory of Oncoendocrinology at Petrov Research Institute of Oncology (St Petersburg, Russia) \& a member of the Council of Russian Endocrine Association. Can you tell our readers what these roles entail? How do you balance your time between these roles?}

The differences between these duties are significant. The laboratory is my main responsibility. 
We make all efforts to organize its work in a western manner, in other words laboratory staff members are involved in both clinical work as physicians and laboratory work as researchers. Such a combination is not always easily achievable; however, it undoubtedly helps us to be more aware of patients' needs and, thus, to realize the direction of science that needs to be developed.

To be a member of the Council of Russian Endocrine Association is, on one hand, an honorary mission and, on the other hand, a sort of public activity, which involves taking part in its running, as well as making presentations at conferences and training courses organized by the association. In recent years, such events increasingly address issues related to cancer endocrinology, including not only endocrine gland tumors, but also much more prevalent cancers of hormone-dependent tissues. This evidences the growing significance of this research trend for 'pure' endocrinologists.

\section{- One of your main scientific interests is studying the risk factors of hormone-associated tumors. What social changes would you like to see occur that would aid in its prevention \& treatment?}

Let us take breast and endometrial cancers as examples. It is known that risk factors of hormone-associated tumors are often categorized as reversible and irreversible. The reversible ones (from the behavioral and social stand point) include body mass control by diet and physical activity, alcohol consumption and tobacco smoking. All these factors are partially mediated, in different ways, by the endocrine system. For example, tobacco smoking does not always modify estrogens in circulation but undoubtedly influences estrogen metabolism (hydroxylation) and target tissue sensitivity to estrogens. However, the association between cancer and smoking (so as between cancer and oral contraceptives) features some subtleties of its own. In fact, in women who smoke and who start using steroid contraceptives early, an increase in breast cancer risk and, on the contrary, a decrease in endometrial cancer risk is reported. Nevertheless, it should be stressed (leaving the issue of oral contraceptive aside) that the well-known differences in the prevalence of these two cancers make the cessation of smoking an undoubtedly favorable social choice.

As to cancer treatment, a large body of literature suggests that behaviorally modifiable factors, such as reduced physical activity, excessive body mass/caloric intake and smoking, usually worsen the prognosis for patients with hormonedependent tumors, and often compromise the results of their treatment.

\section{- Your bibliography contains approximately ten monographs \& more than 20 chapters. \\ What do you enjoy about writing these?}

Briefly, I should say that they are Labor, with a capital letter, which does not stop for even a minute after it has started and urges perpetual searching for free time to continue it. On the other hand, you are quite right talking about enjoyment in this context. Working on a voluminous text is associated with the feeling of continuing self-education. Indeed, much new and hopefully useful information is learned in this way, and many ideas that come to mind may be used 'here and now', as well as sometimes later.

\section{- As an editorial board member of several journals, including Future Oncology, Voprosy Onkologii (Problems of Oncology) \& Expert Review of Endocrinology \& Metabolism, can you tell our readers what you enjoy most about these positions?}

My responsibilities in these journals are notably different. In the leading Russian journal Voprosy Onkologii (Problems of Oncology), I have been the executive secretary of its editorial board for over 20 years. This position implies everyday routine work with submissions, correspondence with their authors, editing, taking part in editorial sitting and so on.

In journals such as Future Oncology and Expert Review of Endocrinology and Metabolism my responsibilities are limited to drawing up of recommendations about the themes of future publications, reviewing of submissions from time to time and submitting my own work $[7,9,11]$. It is a pleasure to remember my relatively recent experience of being one of two guest editors in an issue of Expert Review of Endocrinology and Metabolism that was dedicated to breast and prostate cancer-related problems [12].

\section{What research are you currently involved in?}

At present, the group's attention is focused on the differences between diabetic patients with and without cancer. In particular, we want to find out whether there are differences in their sensitivities to the antidiabetic biguanide metformin and what the role of family predisposition to diabetes is in this regard. We are also still alert to the fact that obesity is so heterogenous 
that it should not be marked with a single ink, and this variability may be reflected in differential cancer risks and cancer patient survival rates [7].

\section{- What are the current 'hot topics' in oncoendocrinology research?}

It is clear that no science is now viable without novelty; however, no science is viable without 'gold standards' too, and cancer endocrinology is no exception. A typical 'gold standard' in this field implies, in particular, the expediency of defining the receptor phenotype of breast cancer tissue as an 'until-now criterion' for further treatment. Innovations are often based on methodological advances (e.g., genomics extending up to whole-genome analysis, proteomics and mass spectrometry) and find their culminations being combined with good ideas. In this regard, the idea that breast cancer comprises several biological subtypes is revolutionary in its own right, not only because it is consistent with the claim that cancer treatment should be individualized based on 'the molecular portrait of a tumor' [13], but also because it points at a very important thing (which is long known, in principle): with all the similarities between different cases of a particular disease, each case is individual and, at the same time, is attributable to several general or typical groups. Therefore, a 'hot topic' in oncoendocrinology is certainly the analysis, which attracts ever increasing interest, of the hormonal features (in the broad sense of this word) of breast cancer [13] and, no less importantly, endometrial cancer subtypes [14]. Trying to be succinct, I cannot fail to mention problems such as the hormonal basis of the hereditary predisposition to cancer, which may be exemplified with BRCA1 mutation-bearing women [7,15], and finding out the reasons, which are very important for understanding the causes of successes and failures in the therapeutic treatment of tumors of hormone dependent-tissues, why cancer resistance to hormonal therapy is inherent (is revealed de novo) in some patients and is acquired in other patients $[16,17]$.

\section{- Finally, what progress do you think will be made in the treatment of hormone-related cancer in the next 10 years?}

The treatment of tumors of hormone-dependent tissues has already advanced quite far. This is especially true for endometrial cancer and thyroid cancer, although certain advances in the treatment of breast cancer and prostate cancer are notable too. In such cases, advances are mostly achieved owing to combinations of endocrine therapy with other approaches, depending on cancer subtype and stage. Thus, surgery for thyroid cancer, especially its highrisk variants, cannot but be followed now by radioiodine therapy. Therapeutic options in prostate cancer treatment have expanded owing to brachytherapy and radical prostatectomy combined with neoadjuvant therapy and, where necessary, 'adjuvant' total androgen blockade (androgen deprivation). As for endometrial cancer, a noticeable decline in the use of hormone therapy is associated in this case with an increasingly prevalent use of chemotherapy and radiotherapy. Such transitions are even more evident in the field of breast cancer treatment where, besides surgery and radiotherapy, the use of antiestrogens, aromatase inhibitors, gonadotropin-releasing factor agonists and, of course, chemotherapy is increasingly often supplemented with targeted medications, mostly monoclonal antibodies or small molecules. To sum up, it is obvious that one of the reasons behind current and, probably future, therapeutic advances is the use of well-grounded and rational combinations of different approaches, including the use of relatively novel drugs, such as CYP17 inhibitors for prostate cancer and steroid sulfatase inhibitors for breast cancer. Another reason, and quite obvious too, is the personalization of treatment, in particular based on genetic (e.g., expression analysis), immunohistochemical and more sophisticated approaches, which make it possible to characterize tumor tissue in a more optimal way (unfortunately, leaving the systemic body conditions aside). The third reason, the one we have begun with here, may be seen in basic science breakthroughs. Such breakthroughs will hopefully make it possible to, for example, prompt measures that can transform receptor-negative breast cancer into a receptor-positive one, thus increasing the efficacy of its treatment; whether there are motives to hope for a hormone therapy for colorectal cancer (which is marginally responsive to steroids, but whose dependence on insulin/insulin-like growth factors and some gut hormones is quite evident); or whether there are reasons to expect that aromatase inhibitors will be, at minimum, as useful in therapy for the endometrial cancer, as they are in therapy for breast cancer, for example. Altogether, this may not only help to better treat hormonedependent cancers, but also may promote the significance and prestige of oncoendocrinology as a field. 


\section{Disclaimer}

The opinions expressed in this interview are those of the interviewee and do not necessarily reflect the views of

Future Medicine Ltd.

Financial \& competing interests disclosure

$L M$ Berstein has no relevant affiliations or financial

involvement with any organization or entity with a financial interest in or financial conflict with the subject matter or materials discussed in the manuscript. This includes employment, consultancies, honoraria, stock ownership or options, expert testimony, grants or patents received or pending, or royalties.

No writing assistance was utilized in the production of this manuscript.

\section{References}

1. Dilman VM. Age-associated elevation of hypothalamic threshold to feedback control, and its role in development, ageing, and disease. Lancet 1(7711), 1211-1219 (1971).

2. Botstein D. Why we need more basic biology research, not less. Mol. Biol. Cell 23, 4160-4161 (2012).

3. Berstein LM, Zheng H, Yue W et al. New approaches to the understanding of tamoxifen action and resistance. Endocr. Relat. Cancer 10(2), 267-277 (2003).

4. Berstein LM. Role of endocrine-genotoxic switchings in cancer and other human diseases: basic triad. Adv. Exp. Med. Biol. 630, 35-51 (2008).

5. Berstein LM. Newborn macrosomy and cancer. Adv. Cancer Res. 50, 231-278 (1988).

6. Berstein L. Macrosomy, Obesity and Cancer. Nova Science Publishers, NY, USA (1997).
7. Berstein LM. Cancer and heterogeneity of obesity: a potential contribution of brown fat. Future Oncol. 8, 1537-1548 (2012).

8. Berstein LM. Diabetes, obesity and cancer: risk and anti-risk factors. Diabetes Mellitus 4(57), 81-88 (2012) .

9. Berstein LM. Modern approach to metabolic rehabilitation of cancer patients: biguanides (phenformin and metformin) and beyond. Future Oncol. 6, 1313-1323 (2010).

10. Berstein LM. Metformin in obesity, cancer and aging: addressing controversies. Aging (Albany NY) 4, 320-329 (2012).

11. Berstein LM. Endocrinology of the wild and mutant BRCA1 gene and types of hormonal carcinogenesis. Future Oncol. 4, 23-39 (2008).

12. Berstein LM. Endocrinology of breast cancer: results, tasks and hopes. Expert Rev. Endocrinol. Metabol. 6, 293-297 (2011).

13. Perou CM, Sørlie T, Eisen MB et al. Molecular portraits of human breast tumours. Nature 406, 747-752 (2000).
14. Evans T, Sany O, Pearmain P, Ganesan R, Blann A, Sundar S. Differential trends in the rising incidence of endometrial cancer by type: data from a UK population-based registry from 1994 to 2006. Br. J. Cancer 104(9), 1505-1510 (2011).

15. Rosen EM, Fan S, Isaacs C. BRCA1 in hormonal carcinogenesis: basic and clinical research. Endocr. Relat. Cancer 12, 533-548 (2005).

16. Gee JM, Howell A, Gullick WJ et al. Consensus statement. Workshop on therapeutic resistance in breast cancer: impact of growth factor signalling pathways and implications for future treatment. Endocr. Relat. Cancer 12 (Suppl. 1), S1-S7 (2005).

17. Santen RJ, Fan P, Zhang Z, Bao Y, Song RX, Yue W. Estrogen signals via an extra-nuclear pathway involving IGF-1R and EGFR in tamoxifen-sensitive and -resistant breast cancer cells. Steroids 74, 586-594 (2009). 